\title{
A Study on Prevalence of Thyroid Function Disorders Amongst The Population of Barpeta District, Assam.
}

\author{
Dr. Dipti Bania ${ }^{1}$.Dr. Kakoli Das ${ }^{2}$. \\ ${ }^{1,2}$ Associate Professor. Department Of Physiology. Fakhruddin Ali Ahmed Medical College, \\ Barpeta.Assam,India
}

\begin{abstract}
Introduction and objectives -Thyroid diseases are amongst the commonest endocrine disorders worldwide. India too is no exception. In India sub Himalayan belt extending from Kashmir to Assam is well a recognized area of endemic iodine deficiency. The main aim of the study was to find out the prevalence of thyroid disorders amongst the adult population of Barpeta town and to create awareness among the population about the disorder. Material and methods- The current study was a cross sectional study conducted in the Barpeta district, Assam at Fakhruddin Ali Ahmed Medical College and Hospital. 600 participants were included in the study after taking proper consent after explaining the procedure to each subjects. Assays for thyroid hormones $(T 3, T 4)$ and TSH were performed by Electrochemiluminescence(ECL) technology using Immunoassay analyzer Roche Cobas e411. Anti TPO antibodies were also measured by the same analyzer. The prevalence of different thyroid function disorders was summarized as count and percentages. A chi square test was used to assess the trends in the prevalence of the disorders among different age groups and genders.

Result- Of the total study population 443 (73.83\%) subjects had normal levels of serum T3, T4 and TSH values without history of thyroid medication. Other 157 (26.17\%) subjects had abnormal serum thyroid hormones and TSH levels, who were categorized as hypothyroid, subclinical hypothyroid, hyperthyroid and subclinical hyperthyroid. The prevalence of hypothyroidism in the overall study population was $9.67 \%(n=58)$, of which6.33\%(n=20) were self reported cases and $6.33 \%(n=38)$ were previously undetected. Subclinical hypothyroidism was observed in $4 \%$ of the study population. Hyperthyroidism - a total of $25(4.17 \%)$ participants including 14 females were diagnosed with hyperthyroidism. Subclinical hyperthyroidism was seen in 10 subjects including 6 female subjects though significant association between the frequency of the disorder with age or gender was not seen. Anti TPO antibody positivity was seen in 40 subjects without significant variation as per gender and age.

Conclusion- Our study demonstrates that hypothyroidism was higher in the older adults with a female preponderance and there is a significant prevalence of hyperthyroidism too.
\end{abstract}

Keywords:TSH, T3, T4, hypothyroidism, hyperthyroidism

\section{Introduction}

Serum TSH measurement is the most important and sensitive test of screening of hypothyroidism, because, serum TSH has a long linear relationship with circulating thyroid hormone level. A twofold change in the free thyroxin will produce a 100 fold change in the TSH [1]. Sign and symptoms of overt hyper and hypothyroidism are well known, subclinical thyroid condition have subtle clinical manifestation and may mimic other diseases. Hence it is important develop national laboratory strategies to differentiate the various conditions to guide the physicians towards correct diagnosis and treatment [2].

Thyroid diseases are arguably amongst the commonest endocrine disorders worldwide .India too is no exception. According to a project from various studies on thyroid diseases, it has been estimated that about 42 million people in India suffer from thyroid diseases [3]. Almost one third of the Indian population lives in the areas of Iodine deficiency [3] .Iodine deficiency disorder is a major public health problem in India. When dietary intake of iodine falls down to 10 microgram per day thyroid hormone synthesis is inadequate and secretion declines [4].Its deficiency leads to a host of physical and neurological abnormalities which are collectively referred to as IDD ( Iodine deficiency disorders).In a developing and diversely populated country like India communicable diseases are priority health concern due to their large contribution to the national disease burden[5]. In India hypothyroidism was usually categorized under the cluster of IDD, which were represented in terms of total goiter rate and urinary iodine concentration, typically assessed in school aged children [5,7,8].Even since India adopted the universal salt Iodization program in 1983 [9], there has been a decline in goiter prevalence in several parts of the country, which were previously endemic[10,11,12]. A recent 
review of studies conducted in post iodization phase gives some indication of the corresponding change in the thyroid status of the Indian population[13].In India sub Himalayan belt extending from Kashmir to Assam is well a recognized area of endemic iodine deficiency. Though a large cross sectional study was required to provide a clearer picture of the evolving thyroid profile of the area, due to certain limitation we conducted a localized cross sectional study. The main aim of the study was to find out the prevalence of thyroid disorders amongst the adult population of Barpeta town and to create awareness among the population about the disorder, so that early diagnosis and adequate management is possible which will prevent development of further systemic complication related to abnormal thyroid status.

\section{Material And Methods}

The current study was a cross sectional study conducted in the Barpeta district, Assam at Fakhruddin Ali Ahmed Medical College and Hospital. The study was conducted after obtaining the ethical clearance from the institutional ethics committee. This study was conducted from January 2016 to January 2017.A total 600 participants were included in the study after taking proper consent on explaining the procedure to each subjects. All male and female patients referred to central laboratory for thyroid function tests were included in the study excluding them who were under any medication for thyroid diseases. Besides participants were excluded if they are pregnant or have any acute or chronic systemic diseases or if they were receiving drugs like lithium or steroids which could interfere with thyroid function tests.

All the subjects underwent general clinical examination before enrollment including examination of the thyroid gland. Routine haematological and biochemical investigations were done for all subjects. Evaluation of thyroid profile was done in the central clinical laboratory of our hospital.

Assays for thyroid hormones (T3, T4) and TSH were performed by Electrochemiluminescence(ECL) technology using Immunoassay analyzer Roche Cobas e411. Anti TPO antibodies were also measured by the same analyzer. definitions-

Based on the previous history and present thyroid function status, participant were classified following

Hypothyroid-Serum thyroxin (T4) $<5 \mathrm{ng} / \mathrm{ml}$ and $\mathrm{TSH}>5.50 \mu \mathrm{U} / \mathrm{ml}$.

Hyperthyroid- T4 $>14 \mathrm{ng} / \mathrm{ml}$ and $\mathrm{TSH}<0.35 \mu \mathrm{U} / \mathrm{ml}$.

Subclinical hypothyroidism-normal serum T4 and TSH $>5.50 \mu \mathrm{U} / \mathrm{ml}$

Subclinical hyper thyroidism - normal serum T4 and TSH $<0.35 \mu \mathrm{U} / \mathrm{ml}$.

AntiTPO antibody positive - Presence of Anti TPO antibody above $35 \mathrm{IU} / \mathrm{ml}$.

The prevalence of different thyroid function disorders was summarized as count and percentages. A chi square test was used to assess the trends in the prevalence of the disorders among different age groups and genders.

\section{Results}

Six hundred participants were enrolled from Barpeta district from August 2015 to August 2016. Out of this 600 participants $350(56.33 \%)$ were male and $250(41.67 \%)$ were female. The mean age was 41.24 years with a range of 19 to 82 years. All the participants were reportedly consuming iodized salt. 90 subjects $(15 \%)$ of the study group gave a history of thyroid dysfunction including thyroid surgery. Thyroid medications were currently used by around $10 \%$ of the study population. The age wise and the gender wise breaking of the study group are explained by the TABLE 1 and 2 respectively.

Of the total study population 443 (73.83\%) subjects had normal levels of serum T3, T4 and TSH values without history of thyroid medication. Other 157 (26.17\%) subjects had abnormal serum thyroid hormones and TSH levels, who were categorized as hypothyroid, subclinical hypothyroid, hyperthyroid and subclinical hyperthyroid.

The prevalence of hypothyroidism in the overall study population was $9.67 \%(\mathrm{n}=58)$, of which6.33\%(n=20) were self reported cases and $6.33 \%(n=38)$ were previously undetected. Out of the 20 self reported cases 12 were under thyroxin therapy.

Logistic regression analysis demonstrated a statistically significant $(\mathrm{p}<0.05)$ interaction of subjects age and gender with the prevalence of hypothyroidism. As compared to the young adults (20-39years) group, older adults group had greater chances of being diagnosed as hypothyroid. However in population above 65 years comparatively lesser prevalence of hypothyroidism recorded. Prevalence of hypothyroidism was highest in the age group of 40-64 years $(4.16 \%)$ and lowest in the age group of $>65$ years $(1.67 \%)$. A larger population of females than males was found to be affected by hypothyroidism (6.33\%vs4\%). Subclinical hypothyroidism was observed in $4 \%$ of the study population. Frequency of subclinical hypothyroidism is lowest $(1.33 \%)$ in age group of above 65years and highest (4.16\%) in the age group of 40-64 years. A significantly higher number of females $(2.5 \%)$ than males $(1.5 \%-6 \%)$ were detected to have $\mathrm{SCH}$. 
A total of $25(4.17 \%)$ participants including 14 females were diagnosed with hyperthyroidism. There was no association between hyperthyroidism and age or gender. Subclinical hyperthyroidism was seen in 10 subjects including 6 female subjects though significant association between the frequency of the disorder with age or gender was not seen. Anti TPO antibody positivity was seen in 40 subjects without significant variation as per gender and age.

Table 1-gender wise distribution of study group.

\begin{tabular}{|l|l|l|}
\hline Total & $\mathrm{N}=600$ & $100 \%$ \\
\hline Male & 350 & $56.33 \%$ \\
\hline Female & 250 & $41.67 \%$ \\
\hline
\end{tabular}

Table 2- Age wise distribution of the study group.

\begin{tabular}{|l|l|l|}
\hline Age (years) & $\mathrm{N}=600$ & $\%$ \\
\hline $20-39$ & 175 & 19.16 \\
\hline $40-64$ & 325 & 54.16 \\
\hline$>65$ & 100 & 16.67 \\
\hline
\end{tabular}

Table 3-overall prevalence of

\begin{tabular}{|l|l|l|}
\hline Type of disorder & Number of subjects & $\%$ \\
\hline Hypothyroidism & 58 & $9.67 \%$ \\
\hline Subclinical hypothyroidism & 24 & $4 \%$ \\
\hline Hyperthyroidism & 25 & $4.17 \%$ \\
\hline Subclinical hyperthyroidism & 10 & $1.6 \%$ \\
\hline Anti TPO positive & 40 & $6.67 \%$ \\
\hline
\end{tabular}

thyroid disorders in the study population.

Table 4- gender wise distribution of the thyroid disorders.

\begin{tabular}{|l|l|l|}
\hline Types of disorders & Female $(\mathrm{n}=350)$ & Male $(\mathrm{n}=250)$ \\
\hline Hypothyroidism(58) & $38(6.33 \%)$ & $24(4 \%)$ \\
\hline Subclinical hypothyroidism(24) & $15(2.5 \%)$ & $9(1.5 \%)$ \\
\hline Hyperthyroidism(25) & $14(2.3 \%)$ & $11(1.83 \%)$ \\
\hline Subclinical hyperthyroidism(10) & $6(1 \%)$ & $4(0.67 \%)$ \\
\hline
\end{tabular}

Table 5- Age Wise Distribution Of The Study Group With Different Thyroid Disorders

\begin{tabular}{|l|l|l|l|}
\hline Disorder & $20-39$ years & $40-64$ years & $>65$ years \\
\hline Hypothyroidism (58) & $23(3.83 \%)$ & $25(4.16 \%)$ & $10(1.67 \%)$ \\
\hline $\begin{array}{l}\text { Subclinical } \\
\text { hypothyroidism(24) }\end{array}$ & $7(1.67 \%)$ & $15(4.16 \%)$ & $2(0.33 \%)$ \\
\hline Hyperthyroidism(25) & $10(1.67 \%)$ & $11(1.83 \%)$ & $4(0.67 \%)$ \\
\hline $\begin{array}{l}\text { Subclinical } \\
\text { hyperthyroidism(10) }\end{array}$ & $3(0.5 \%)$ & $4(0.67 \%)$ & $3(0.5 \%)$ \\
\hline
\end{tabular}

\section{Discussion}

In the current study we assessed the prevalence of thyroid disorders particularly hypothyroidism in population residing in Barpeta District, Assam. Hypothyroidism was found to be a common cause of thyroid dysfunction affecting $9.67 \%$ of population. This observation has similarity with a study conducted in other parts of India suggesting the nationwide higher prevalence of hypothyroidism in India[14,15,16].This suggests the requirement of regular monitoring of the thyroid status of the population who are at greater risk of developing hypothyroidism particularly the older adult group. Exposure to industrial and agricultural contaminants has been identified as one of the thyroid disruptors as a matter of concern. Prevalence of subclinical hypothyroidism was $4 \%$ indicating that a significant proportion of the population may go undetected and untreated even if it impairs their quality of life. In general India is now considered to be in the post iodization phase. Our result suggests that nationwide, the prevalence of hypothyroidism in adult is very high in this era. Unfortunately we did not get any data on the prevalence of hypothyroidism in adult in pre iodization phase.

There was a predominance of thyroid dysfunction in women in our study, and is consistent with worldwide report specially those in midlife. There is always a association between thyroid disorders and cardiovascular risk factors such as hypertension and dyslipidaemia[13] , the prevalence figure observed for women in this study suggest growing health needs of this important segment of the population. In a population based study done in Cochin on 971 adult people, the prevalence of hypothyroidism was 3.9\%. The prevalence of subclinical hypothyroidism was also high in this study $(9.4 \%)[15]$.Current study has observed the consistent result with that. 
Prevalence of hyperthyroidism has been studies in several studies. In an epidemiological study in Cochin , Subclinical and overt hyperthyroidism was found in $1.6 \%$ and $1.3 \%$ of subjects in a community Survey [16]. Similar result has been observed in the current study. In a study in Puduchery on women overt hyperthyroidism was present in $0.6 \%$ study population[17]. In contrast in the current study we are getting $2.3 \%$ women having overt hyperthyroidism. Hyperthyroidism is also a subject of concern for urgent intervention.

\section{Conclusion}

Our study demonstrates that hypothyroidism was higher in the older adults with a female preponderance and there is a significant prevalence of hyperthyroidism too. This Indicate thyroid function screening should be a part of laboratory investigation in this susceptible group of population followed by appropriate detection and management. Despite the coverage of national iodine deficiency control program in India iodine deficiency is still prevalent in many parts of India[18].

\section{References}

[1]. Vahab Fatourechi (2006) .what is normal TSH? Mayo clinic college of Medicine, US

[2]. (Heuk cc, Kallen A, Kanegasabapathy AS, Riesen w. WHO document ( WHO/DIL/00.4" On diagnosis and monitoring of diseases of thyroid 2000 13).

[3]. Available from :http//wwwias.ac.in/currsci/oct25000/20 kochu pillai .PDF

[4]. Chatterjee, M.N.and Shinde, R.Medical Biochemistry, $2^{\text {nd }}$ edn. P734(1995).

[5]. New Delhi: Background Papers- Burden of diseases in India; 2005. National commission on macroeconomics and Health Ministry of Health And Family Welfare, Government of India.

[6]. Sood A, Pandav CS, Anand K, Sankar R, Karmakar MG. Relevance and importance of universal salt iodization in India.Natl Med J India. 1997:10: 290-3

[7]. Kapil U, Saxena N, Ramachandran S, Balamurugan A, Nayar D, Prakash S. Assessment of iodine deficiency disorders using the 30 cluster approach in the National capital Territory of Delhi. Indian Pediatr 1996; 33: 1013-7

[8]. M. Dodd NS, Godhia ML. Prevalence of iodine deficiency disorders in adolescents. Indian J Pediatr.1992;59: 1013-7

[9]. Tiwari BK, Ray 1, Malhotra RL. NEW Delhi . Government of India ; 2006. Policy guidelines on national iodine deficiency disorders control program -Nutrition And IDD cell. Directorate of health services, Ministry of health and family welfare ; pp 1-22.

[10]. Toteja GS, Singh P, Dhilon BS, Saxena BN . Iodine Defiency disorders in 15 districts of India .Indian J pediatr. 2004 ; $71.25-8$.

[11]. Marwaha RK, Tendon N, Gupta N, Karak AK, Verma K, Kochupillai N. Residual Goitre in the postiodization phase: Iodine status , Thyocyonate exposure and autoimmunity. Clin. Endocrinology ( oxf)2003;59: 672-81.

[12]. Kapil U , Sharma TD, Singh P. Iodine status and goiter prevalence after 40 years of salt iodization in Kangra District, India . Indian J Pediatr. 2007; 74: 135-7.

[13]. Luboshitzky R, Herer P. Cardiovascular risk factors in middle aged women with subclinical hypothyroidism. Neuroendocrinol let. 200425:262-6

[14]. Gopalakrishnan Unnikrishinan A . Prevalence of hypothyroidism in adult: An epidemiological study in eight cities of India.Indian J Endrocrinol Metab.2013 Jul-Aug; 17(4) 647-652

[15]. Unnikrishnan AG, Menon UV. Thyroid disorders in India. An epidemiological perspective . Indian J Endicrinol Metab.2011;15;S78-81

[16]. Usha menon V. et Al High prevalence of undetected thyroid disorders Iodine sufficient adult of south Indian population.J. Indian Medical Association. 2009.107.72-7.

[17]. Abraham R, et AI Thyroid disorders in women of Puducherry.Indian J. clin Biochem.2009 .24. 52-9.

[18]. Vir SC Current status of iodine deficiency diseases and strategy for its control in India . Indian J Pediator 2002 69.589-96

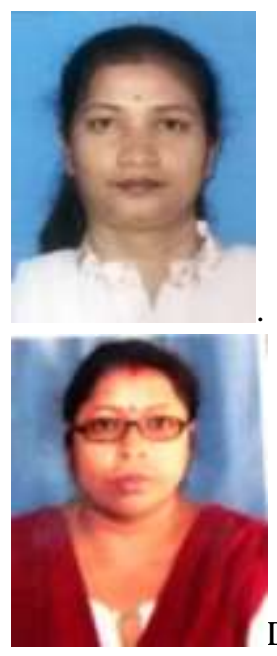

Dr.Dipti Bania MD Physiology. Associated with medical teaching since 2000.

Dr.Kakoli Das . MD Physiology. Associated with medical teaching since 2002. 